\title{
Estudio de la interaccióndel receptor Htr6 de serotonina con las proteínas Cdk5 y TULP3.
}

\author{
Paula Moreno de la Cruz 1, 2, a, Francesc García Gonzalo', b \\ 1. Unidad de Bioquímica y Biología Molecular, Departamento de Biología de Sistemas, Facultad de Medicina y Ciencias \\ de la salud, Universidad de Alcalá, 28871 Alcalá de Henares, Madrid, España. 2. Departamento de Modelos \\ Experimentales de Enfermedades Humanas, Instituto de Investigaciones Biomédicas Alberto Sols, 28029 Madrid, \\ España. \\ a.pmoreno.bm@gmail.com b. francesc.garcia@uam.es
}

Palabras clave: Cdk5; CLS; dominio C-terminal; dominio N-terminal; Htr6; TULP3

\section{Resumen}

Los cilios primarios son prolongaciones de la membrana plasmática en cuya membrana hay una gran cantidad de canales iónicos y receptores como los GPCRs. En concreto, nuestro estudio lo centramos en el receptor ciliar Htr6 de serotonina, el cual es un GPCR de la familia de las rodopsinas, de gran importancia a nivel neuronal. Aunque sus mecanismos de señalización son poco conocidos todavía, se ha visto que este receptor interacciona mediante su extremo $\mathrm{C}$-terminal con una gran cantidad de proteínas implicadas en diferentes vías de señalización. Mediante ensayos de coinmunoprecipitación en células HEK293T, hemos estudiado la interacción del receptor Htr6 con una proteína efectora denominada Cdk5, la cual fosforila dicho receptor. Sin embargo, no obtuvimos resultados que confirmen dicha unión. Por otro lado, el tráfico ciliar de las proteínas de membrana al cilio, incluido el receptor Htr6, es poco conocido por lo que en este estudio esclarecemos el mecanismo de transporte. Para ello, realizamos ensayos de interacción por biotinilación en células HEK293T para analizar la interacción del receptor Htr6 con la proteína TULP3, la cual actúa como proteína adaptadora para el tráfico ciliar de proteínas de membrana. En concreto, estudiamos la interacción de la proteína TULP3 completa, y de sus dominios N-terminal y Cterminal con la CLS del dominio C-terminal del receptor Htr6. De acuerdo con el modelo actual que explica el tráfico ciliar de proteínas de membrana, observamos la interacción entre el extremo C-terminal del receptor Htr6 con el dominio C-terminal de la proteína TULP3. Esto nos permitirá conocer el mecanismo de entrada de ciertas proteínas en el cilio.

Cita: Moreno de la Cruz, Paula; García Gonzalo, Francesc (2019) Estudio de la interaccióndel receptor Htr6 de serotonina con las proteínas Cdk5 y TULP3. dianas 8 (2): e201909fa07. ISSN 1886-8746 (electronic) journal.dianas.e201909fa07 http://www3.uah.es/dianas?e201909fa07. URI http://hdl.handle.net/10017/15181

Copyright: @ Moreno-de-la-Cruz P, García-Gonzalo F. Algunos derechos reservados. Este es un artículo open-access distribuido bajo los términos de una licencia de Creative Commons Reconocimiento-NoComercialSinObraDerivada 4.0 Internacional. http://creativecommons.org/licenses/by-nc-nd/4.0/

\section{Introducción}

Los cilios primarios se consideran evaginaciones de la membrana plasmática formadas a partir de un cuerpo basal cuya estructura se asemeja a un centriolo, y en cuyo interior podemos encontrar una matriz y un axonema microtubular. Entre el cuerpo basal y el axonema tenemos la zona de transición. En la membrana ciliar podemos encontrar canales iónicos y receptores como los GPCRs (receptores acoplados a proteínas G) de la familia de la rodopsinao clase A [1]. La principal función de los cilios primarios es actuar como antena sensorial captando y transduciendo diversas señales ópticas, mecánicas y químicas. También juegan un importante papel durante el desarrollo embrionario y en la función de varios tejidos.

Existen un conjunto de enfermedades raras, denominadas ciliopatías, causadas por defectos en ciertos genes implicados en la estructura y/o función del cilio. Estas ciliopatías se manifiestan en anomalías cerebrales, degeneración de la retina y enfermedades renales, y son consideradas enfermedades raras que se producen generalmente como consecuencia de mutaciones en genes necesarios para la función ciliar como es el caso del Síndrome de Bardet-Bield [2]. Esta ciliopatía se desarrolla como consecuencia de mutaciones en el complejo de transporte generando cambios en la composición proteica de la membrana ciliar, como por ejemplo en la cantidad de GPCRs.

Los GPCRs son receptores transmembrana acoplados a proteínas G, los cuales están formados por siete dominios transmebrana conectados por tres intracelulares y tres extracelulares, y por dos terminales, el N-terminal y el C-terminal. La unión del ligando correspondiente al GPCR genera un cambio conformacional en el receptor que conlleva a la activación de una proteína $\mathrm{G}$ activando así su vía de señalización. Sin embargo, también se ha visto activación independiente de ligando.

En concreto, vamos a estudiar el receptor Htr6 de serotonina, el cual localiza en los cilios primarios de las células del sistema nervioso y, además, es el único receptor de serotonina presente en el cilio [3][4]. Este tiene como ligando a la serotonina; y su unión va a producir la activación de una proteína G estimuladora, activando así la vía de señalización de adenilato ciclasa, así como la de mTORC1 [5]. Mediante diversos 
estudios de proteómica se ha visto que el receptor Htr6 interacciona con una gran cantidad de proteínas mediante su extremo C-terminal, como es el caso de la proteína Cdk5. Cdk5 es una serina/treonina quinasa dependiente de la ciclina 5 , cuya función es controlar la dinámica del citoesqueleto de actina en células neuronales. Esta proteína se activa por medio de p35 y p39 en neuronas, y va a activar al receptor Htr6 de manera independiente de ligando. fosforilando la Ser350 de su extremo C-terminal.El receptor fosforilado va activar a Cdc42, GTPasa monomérica de la familia Rho, la cual va a mediar el crecimiento de neuritas [6].

Los GPCRs ciliares, como el receptor Htr6 de serotonina y el receptor Sstr3 de somatostatina, tienen secuencias de localización ciliar (CLSs) situadas en el tercer lazo intracelular (IC3) y en el extremo Cterminal, las cuales determinan el tráfico ciliar de dichos receptores. Estudios anteriores han demostrado que el dominio Ax[S/A]xQ del IC3 de los receptores Htr6 y Sstr3 es una CLS que es suficiente pero no necesaria para la localización ciliar [7]. Posteriormente, mediante estudios de la CLS del extremo Cterminal del receptor Htr6, se ha demostrado que esta CLS se localiza entre los residuos 398 y 403 , debido a que se observa una disminución significativa en la localización ciliar en los mutantes Htr6 Lll398AAA y los mutantes Htr6 PGE401AAA [datos lab. García-Gonzalo, F.].

La entrada de ciertas proteínas ciliares integrales de la membrana, como los GPCRs, al cilio se define en un modelo de tres pasos en el cual la proteína TULP3, miembro de la familia de proteínas tubby, actúa como proteína adaptadora para el tráfico de proteínas "cargo". En el primer paso, la proteína TULP3 se uniría a los $\mathrm{PI}(4,5) \mathrm{P}_{2}$ (fosfoinosítidos 4,5-bifosfato), localizados en la base del cilio, mediante el dominio tubby de su extremo C-terminal. En el segundo paso, se formaría el complejo CLS-TULP3 mediante la unión de TULP3 a la CLS de la proteína que transporta. A continuación, TULP3, mediante su extremo Nterminal se uniría al complejo de transporte intraflagelar IFT-A, el cual se acumula en la zona de transición del cilio, de tal modo que se genera un complejo ternario CLS-TULP3/IFT-A. En el tercer y último paso, se liberaría el GPCR debido a la falta de $\mathrm{PI}(4,5) \mathrm{P}_{2}$ en el cilio ya, que TULP3 deja de reconocer al fosfoinosítido debilitando, por tanto, su interacción con TULP3. Esto va a desencadenar la liberación del GPCR y su transporte al interior del cilio [8] (Figura 1).

Las interacciones de los receptores ciliares con otras proteínas son de gran importancia para poder estudiar la señalización celular que se da en el cilio primario la cual es poco conocida. En este trabajo se va a estudiar por un lado, la unión del receptor Htr6 con la proteína Cdk5, y por otro lado, se analizará la interacción de la proteína TULP3 con el extremo C-terminal del receptor Htr6. El objetivo de este estudio es determinarlos residuos con las que interaccionan dichas proteínas.

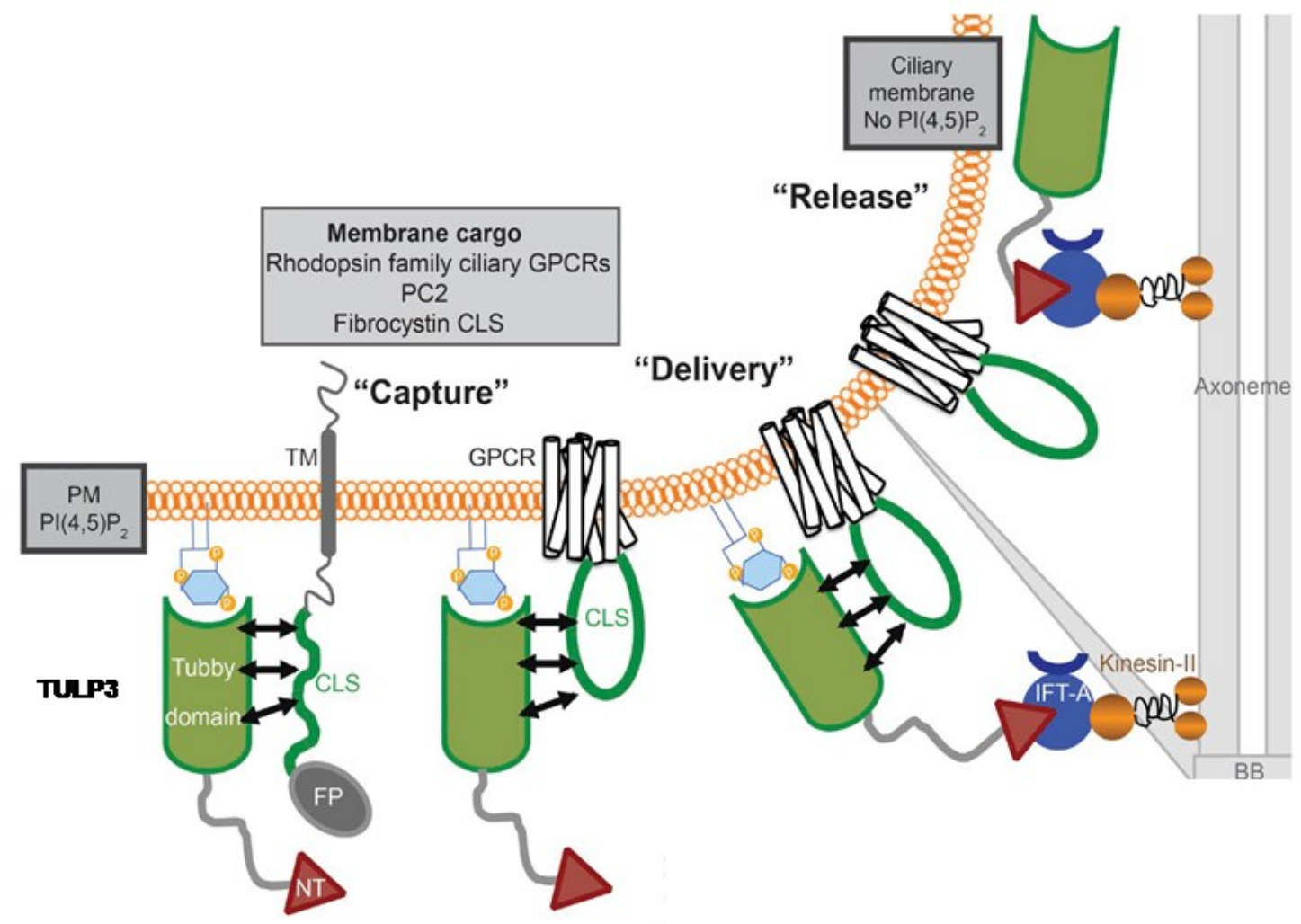

Figura 1.- Modelo de tráfico ciliar de proteínas de membrana al cilio mediante TULP3. BB, cuerpo basal; CLS, secuencia de localización ciliar; FP, proteína de fusión; NT, dominio N-terminal; PM, membrana plasmática. Modificación de Badgandi et al., 2017. 


\section{Material y métodos}

\section{Plásmidos}

En el caso del plásmido pFlag-mCdk5, la secuencia de Cdk5 se obtuvo a partir de ARNm extraído de células MEFs (fibroblastos de embriones de ratón) y a continuación, se realizó una retrotranscripción para obtener el ADNc. El ADNc se amplificó por PCR y se añadió en el extremo 5' la secuencia de ADN de la etiqueta de Flag. Posteriormente, la secuencia de Flag-Cdk5 fue insertada en el vector comercial pEGFP C1(Clontech), en el cual se eliminó la secuencia de EGFP mediante la digestión previa con las enzimas AgeI (ThermoFisherScientific) y KpnI (ThermoFisherScientific).

Para obtener los plásmidos pMyc-Htr6(WT+LLL398AAA), la secuencia de Htr6 wild type fue amplificada por PCR y se añadió en el extremo 5' la secuencia de ADN de la etiqueta de Myc. A continuación, la secuencia de Myc-Htr6 fue introducida en el vector comercial pEGFP_N1 (Clontech), tratado anteriormente con las enzimas XhoI (ThermoFisherScientific) y NotI (ThermoFisherScientific) para eliminar la secuencia de la proteína EGFP. Primero se obtuvo el plásmido con Htr6 wt y después mediante overlap extension PCR se introdujo la mutación LLL398AAA para obtener el plásmido pMycHtr6 LLL398AAA.

Por otro lado, se obtuvieron los plásmidos pMCS-CD8 $\alpha$-CT(GPCRs)-BioID2-HA amplificando las secuencias de CD8 $\alpha$-CT(GPCRs) por PCR y posteriormente, se insertaron en el vector MCS-BioID2-HA [8][9].Primero se obtuvo el plásmido con el extremo C-terminal deB2AR (receptor adrenérgico $\beta 2$ ) y de Htr6 wild type. Mediante PCR de este último plásmido, se generaron las secuencias de los dominios Cterminales de los mutantes Htr6 $6_{\text {Ll } 398 A A A}, H \operatorname{tr} 6_{\triangle 373-440 y} \operatorname{Htr}_{\Delta 408-440}$, las cuales se insertaron en el vector MCS-BioID2-HA.

Los plásmidos pGLAP-hTULP3 y pGLAP-hTULP3(NTD+CTD) se generaron amplificando la secuencia completa de TULP3 la cual se insertó en el vector pG-LAP5 [8]. A continuación, mediante PCR se generaron las secuencias del dominio N-terminal y C-terminal de TULP3 las cuales se insertaron posteriormente en el vector pG-LAP5.

\section{Transfección}

Para el proceso de transfección usamos células HEK293T (“ATCC"), células embrionarias de riñón humano 293, las cuales fueron cultivadas en medio DMEM (SIGMA) con $10 \%$ de FBS (gibco) a $37^{\circ} \mathrm{C}$ y $5 \%$ de $\mathrm{CO}_{2}$.

El día anterior a la transfección, se añadieron 400.000 células/ml en placas P100 a partir de un cultivo de HEK293T para obtener una confluencia del 70-80\% en el momento de la transfección. Esta se llevó a cabo mediante el método químico de fosfato de calcio. Los reactivos usados para dicha transfección fueron2' $5 \mathrm{M}$ de cloruro cálcico $\left(\mathrm{CaCl}_{2}\right), 25 \mu \mathrm{M}$ de Cloroquina (AcrosOrganics, 455240250) y tampón HBS $2 \mathrm{X}, 50 \mathrm{mM}$ de compuesto de HEPES, $280 \mathrm{mM}$ de cloruro sódico $(\mathrm{NaCl})$ y 1'5 $5 \mathrm{mM}$ de $\mathrm{Na}_{2} \mathrm{HPO}_{4}$.

Una vez transfectadas las células, se sustituyó el medio de transfección por DMEM con 10\% de FBS a las 4-16 después de la transfección.

\section{Estudio de interacción por co-inmunoprecipitación}

Las células HEK293T fueron transfectadas con $5 \mu \mathrm{g}$ de cada plásmido; con el plásmido pCMV-myc (vector vacío) o Myc-Htr6 (wild type ó mutante), y con el plásmido pFlag-Cdk5.

En el caso de las células a las que se añadió serotonina (5HT), a las \pm 32 horas después de la transfección, se ayunaron las células cambiando el medio de cultivo por DMEM con 0,2\% de FBS y se incubaron durante 16 horas a $37^{\circ} \mathrm{C}$. 5 minutos antes de lisar se añadió $10 \mu \mathrm{M}$ de serotonina a las placas con tratamiento y el vehículo, que en este caso de $\mathrm{H}_{2} \mathrm{O} \mathrm{mQ}$, a las placas sin tratamiento.

A las 40-48 horas post-transfección, se recogieron las células utilizando PBS 1X frío y se lisaron en 50 $\mathrm{mM}$ de Tris- $\mathrm{HCl} \mathrm{pH} 7.5,150 \mathrm{mM}$ de $\mathrm{NaCl}, 0.5 \mathrm{mM}$ de EDTA, 1\% Igepal CA-630 (Sigma-Aldrich), 10\% glicerol, $1 \mathrm{X}$ cóctel de inhibidores de proteasas (Halt, ThermoFisherScientific) y $1 \mathrm{X}$ cóctel de inhibidores de fosfatasas (Halt, ThermoFisherScientific) durante 1 hora a $4^{\circ} \mathrm{C}$ con agitación orbital. Los lisados se centrifugaron a $20.000 \mathrm{xg}$ durante 10 minutos a $4^{\circ} \mathrm{C}$ y después se extrajeron $35 \mu \mathrm{l}$ para estudiar la expresión de nuestras proteínas y el resto se inmunoprecipitó mediante las beads magnéticas Myc-Trap (Chromotek). Para separar las proteínas inmunoprecipitadas de las beads, estas se incubaron en Laemmli $2 \mathrm{X}$ y $200 \mathrm{mM}$ de DTT de tres maneras distintas: a $37^{\circ} \mathrm{C}$ durante 40 minutos, a $60^{\circ} \mathrm{C}$ durante 15 minutos y a $95^{\circ} \mathrm{C}$ durante 5 minutos. En el caso de las células incubadas con serotonina, se realizó un único tratamiento, $60^{\circ} \mathrm{C}$ durante 15 minutos.

Las IPs y los lisados fueron analizados por Western Blot siguiendo protocolos estandarizados. Se utilizó el anticuerpo de ratón contra la proteína Cdk5 (Sigma-Aldrich) para observar la expresión e 
inmunoprecipitación de la proteína $\mathrm{Cdk} 5$, y por otro lado, se utilizó el anticuerpo de ratón contra la etiqueta de Myc (Santa Cruz) para analizar la expresión de Htr6(WT y mutante) e inmunoprecipitación.

\section{Ensayo de proximidad por biotinilación.}

Las células HEK293T fueron transfectadas con $5 \mu \mathrm{g}$ de cada plásmido; con el plásmido, MSC-CD8 $\alpha$ CT(GPCRs)-BioID2-HA, y con el plásmido pGLAP-Tulp3(proteína completa, dominio N-terminal o dominio C-terminal). A las \pm 32 horas post-transfección, se añadió $50 \mu \mathrm{M}$ de Biotina y se incubaron las células durante 16 horas a $37^{\circ} \mathrm{C}$.

A las 40-48 horas post-transfección, se recogieron las células utilizando PBS 1X frío y se lisaron en 50 $\mathrm{mM}$ Tris- $\mathrm{HCl} \mathrm{pH} 7.5,200 \mathrm{mM} \mathrm{KCl}, 1 \mathrm{mM} \mathrm{MgCl} 2,1 \mathrm{mM}$ EGTA, 10\% glicerol, $1 \mathrm{mM}$ DTT, 0.6\% Igepal CA-630 (Sigma-Aldrich), 1X cóctel de inhibidores de proteasas (Halt, ThermoFisherScientific) durante 30 minutos a $4^{\circ} \mathrm{C}$ con agitación orbital. Los lisados se centrifugaron a $20.000 \mathrm{xg}$ durante 10 minutos a $4^{\circ} \mathrm{C}$, de estos lisados se extrajeron $35 \mu \mathrm{l}$ para estudiar la expresión de nuestras proteínas.

El resto del lisado, se inmunoprecipitó mediante las beads magnéticas GFP-Trap (Chromotek). Las proteínas inmunoprecipitadas con GFP-trap fueron digeridas con la proteasa TEV durante 2 horas a $25^{\circ} \mathrm{C}$. Los sobrenadantes se sometieron a una segunda inmunoprecipitación con la proteína $\mathrm{S}$ agarosa (EMD milipore). Para separar las proteínas inmunoprecipitadas de las beads, estas se incubaron a $95^{\circ} \mathrm{C}$ durante 5 minutos.

Las IPs y los lisados fueron analizados por Western Blot siguiendo protocolos estandarizados. En los lisados se usó el anticuerpo de conejo contra la etiqueta GFP (ProteinTech) para observar la expresión de TULP3, y el anticuerpo de rata contra la etiqueta HA (Chromotek) para analizar la expresión de los constructors de los dominios C-terminales de los receptores con BioID. En el caso de las IPs, se usó neutravidina marcada con HRP (ThermoFisherScientific) para estudiar la señal de biotinilación en el TULP3 inmunoprecipitado, y el anticuerpo de ratón contra la etiqueta S-Tag (Merck Milipore) para analizar la cantidad total de TULP3 inmunoprecipitado.

Este protocolo fue adaptado de Badgandi et al., 2017, y Kim et al., 2016.

\section{Resultados}

\section{No se observa interacción entre Cdk5 y Htr6}

La interacción entre Cdk5 y el dominio C-terminal del receptor Htr6 ya ha sido descrita en células NG108-15, células somáticas híbridas generadas a partir de neuroblastoma de ratón y glioma de rata [6]. Sin embargo, esta interacción no se ha estudiado sobreexpresando dichas proteínas en células HEK293T ni si se produce alguna variación a mutar el receptor.

Por otro lado, se ha observado que la mutación LLL398AAA en el dominio C-terminal del receptor Htr6 ciliar producía una gran disminución del tráfico ciliar de dicho receptor [datos lab. García-Gonzalo, F.]. Es posible que la proteína Cdk5 se una a esta secuencia por lo que vamos a estudiar las diferencias que se producen en la interacción cuando mutamos dicha secuencia.

Para el estudio de la interacción entre la proteína Cdk5 y Htr6 se utilizó el método de la coinmunoprecipitación (CoIP). Para ello, se usaron tres plásmidos que codifican para tres proteínas de fusión distintas: Myc-Htr6, Myc-Htr6 Lll398AAA y Flag-mCdk5. El primer paso fue transfectar células HEK293T con diferentes plásmidos con la intención de que sobreexpresaran por un lado, pMyc-Htr6 y pFlag-Cdk5, y por otro lado, pMyc-Htr6 LlL398AAA y pFlag-mCdk5. Además, se utilizó como control células transfectadas con el vector vacío pCMV-myc y el plásmido pFlag-mCdk5. A las 40-48 horas se lisaron las células y se inmunoprecipitaron el receptor Myc-Htr6 y Myc-Htr6 LlL398AAA mediante beads magnéticas Myc-Trap (Chromotek). Una vez realizamos la inmunoprecipitación (IP), analizamos tanto la expresión de las diferentes proteínas de fusión como las proteínas inmunoprecipitadas mediante Western Blot (figura 2).

En este experimento, vamos a utilizar tres tratamientos distintos para separar las proteínas de las beads y así elegir el tratamiento que mejor separe las proteínas de las beads. Vamos a tratarlas a $37^{\circ} \mathrm{C}$ durante 40 minutos, a $60^{\circ} \mathrm{C}$ durante 15 minutos y a $95^{\circ} \mathrm{C}$ durante 5 minutos.

Podemos observar que hubo expresión tanto de los receptores Htr6 y Htr6 LLL398AAA como de la proteína Cdk5 aunque esta proteína se expresa más en células transfectadas con el vector vacío (figura 2A). Podemos ver una buena inmunoprecipitanción de los receptores Htr6 y Htr6 LLL398AAA por lo que el procedimiento se ha llevado a cabo correctamente. Sin embargo, no observamos IP de Cdk5 lo que indica que no hay interacción entre el receptor Htr6 wild type ni su mutante. Además, podemos observar una pequeña cantidad de Cdk5 inmunoprecipitada en los carriles correspondientes a la expresión de los vectores vacíos lo que nos indica que puede estar produciéndose una unión inespecífica a las beads de Myc-Trap. Por otro lado, con respecto a los tratamientos podemos observar que en el caso del tratamiento 
a $95^{\circ} \mathrm{C}$ durante 5 minutos, la forma monomérica del receptor Htr6 (wild type y mutante) se visualiza menos pero en todos los casos la proteína se separa correctamente de las beads (figura 2B).

A

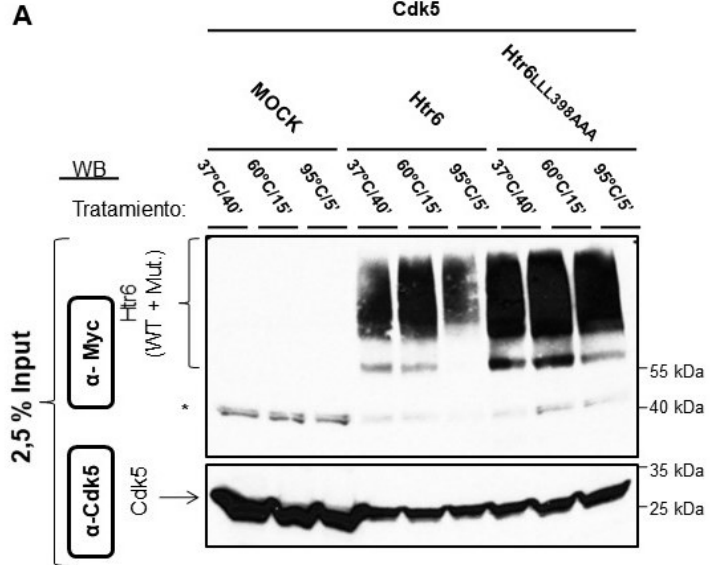

B

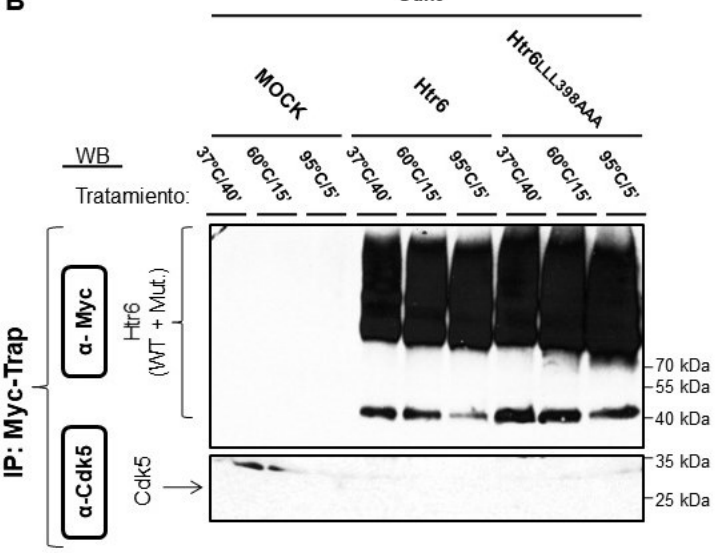

Figura 2.- No hay interacción entre Cdk5 y el receptor Htr6 mediante la inmunoprecipitación del receptor. (A) Western Blot del lisado de proteínas para estudiar la expresión de las diferentes proteínas de fusión. Observamos agregados del receptor Htr6 wt y del mutante pero no observamos la forma monomérica $( \pm 48 \mathrm{kDa})$. * Banda inespecífica del anticuerpo de ratón contra Myc. (B) Western Blot de las proteínas inmunoprecipitadas. Observamos tanto los agregados del receptor Htr6 wt y del mutante como el receptor en su forma monomérica.

\section{La activación del receptor Htr6 con serotonina no favorece la unión de Cdk5 al receptor}

Es posible que en el experimento anterior no observáramos interacción entre Cdk5 y el receptor Htr6 debido a que el receptor se encontraba en su forma inactiva. Para ello, se ayunaron las células 16 horas antes de la lisis y se añadió $10 \mu \mathrm{M}$ de serotonina (5HT) 5 minutos antes de lisar a uno de los casos de células HEK293T transfectadas con los plásmidos pFlag-Cdk5 y el receptor pMyc-Htr6 (figura 3). En este caso, no utilizamos los tres tratamientos sino que se trataron las beads a $60^{\circ} \mathrm{C}$ durante 15 minutos. Además, solo se va a estudiar la interacción de Cdk5 con el receptor Htr6 wild type.

A

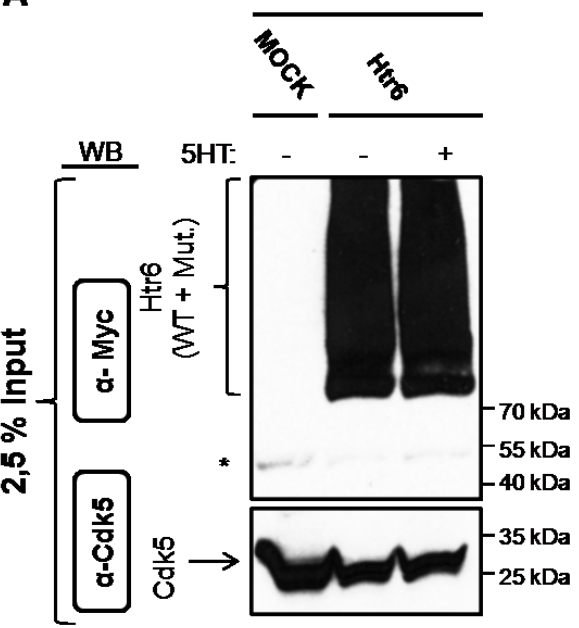

B

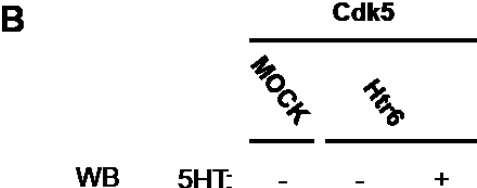

Figura 3.- El tratamiento con serotonina (5HT) no aumenta la cantidad de Cdk5 co-inmunoprecipitada con el receptor Htr6. (A) Western Blot del lisado de proteínas para estudiar la expresión de las diferentes proteínas de fusión. Observamos agregados del receptor Htr6 pero no observamos la forma monomérica $( \pm 48 \mathrm{kDa})$. * Banda inespecífica del anticuerpo de ratón contra Myc. (B) Western Blot de las proteínas inmunoprecipitadas. Observamos tanto los agregados del receptor Htr6 como al receptor en su forma monomérica.

Se observa una elevada expresión tanto del receptor Htr6 como de la proteína Cdk5 (figura 3A). También se ve una buena inmunoprecipitación del receptor Htr6 y se observa algo de inmunoprecipitación de Cdk5 en todos los carriles. Por lo tanto, podemos afirmar que Cdk5 se une de manera inespecífica a las beads de Myc-Trap y que no se está produciendo una unión entre el receptor Htr6 y Cdk5 incluso cuando el receptor se activa mediante serotonina (figura $3 \mathrm{~B}$ ). 
Mutaciones en la CLS del extremo C-terminal del receptor Htr6 producen cambios en la interacción del receptor con TULP3

Actualmente, está descrita la interacción de TULP3 con algunas CLS de GPCRs [8]. Sin embargo, todavía no se ha descrito la interacción de TULP3 con la CLS del dominio C-terminal del receptor ciliar Htr6.

Para estudiar esta interacción, se realizó un ensayo de biotinilación por proximidad en el cual se va a producir un marcaje con biotina cuando las dos proteínas se aproximan. Para ello, usamos una biotinaproteína ligasa denominada BioID para estudiar la proximidad entre los diferentes dominios C-terminales de GPCRs y TULP3. Vamos a estudiar la interacción de TULP3 con el dominio C-terminal del receptor adrenérgico $\beta 2$ (B2AR) el cual no es ciliar (del aminoácido 330 al 413), el dominio C-terminal Htr6 entero (del aminoácido 326 al 440), el dominio C-terminal del mutante Htr6 LLl398AAA cuya mutación disminuye la localización ciliar, el dominio C-terminal del mutante Htr6 ${ }_{\Delta 373-440}$ (del aminoácido 326 al 373), donde no está la CLS y se pierde por completo la localización ciliar, y el dominio C-terminal del mutante Htr6 $\Delta_{\triangle 408-440}$ (del aminoácido 326 al 408) donde no tenemos los últimos residuos pero si la CLS.

En este experimento utilizamos dos fusiones distintas: por un lado, $\mathrm{CD} 8 \alpha$ (secuencia que va del residuo 1 al 208 de la glicoproteína transmembrana CD8) fusionada con los distintos dominios C-terminales de los GPCRs, con la ligasa BioID y con la etiqueta HA; por otro lado, la proteína TULP3 fusionada con la etiqueta Stag, con una secuencia de corte por la proteasa TEV y con la etiqueta EGFP (figura 4).

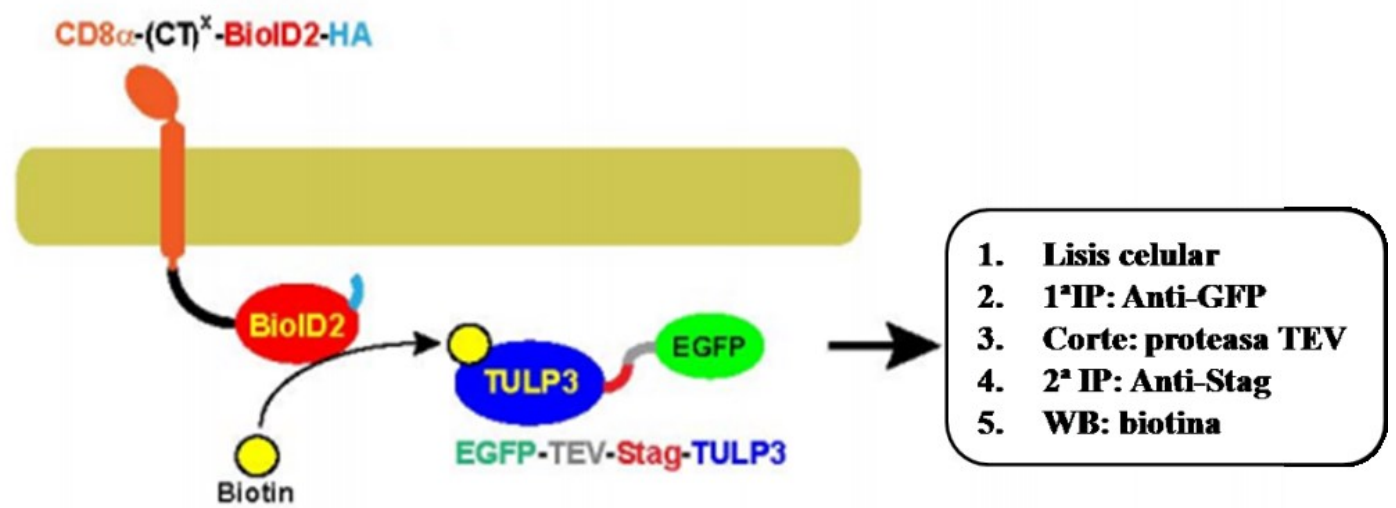

Figura 4.- Esquema de la estructura de las proteínas de fusión y de los pasos a seguir durante el experimento.

Transfectamos las células HEK293T con las fusiones CD8 $\alpha$-CT*-BioID-HA y EGFP-TEV-Stag-TULP3 y después las tratamos con biotina durante 16 horas para que se produzca la unión de biotina a la proteína TULP3 cuando se aproxime al dominio C-terminal gracias a que este tiene unido la biotina-proteína ligasa. Además, vamos a utilizar como control células transfectadas con los vectores vacíos pcDNA3.1()C-myc-His y pEGFP_C1. A las 40-48 horas post-transfección se lisaron las células y se realizó la primera inmunoprecipitación de TULP3 con las beads de GFP-Trap. A continuación, se digirió el inmunoprecipitado con la proteasa TEV seguida de la segunda inmunoprecipitación con la proteína $\mathrm{S}$ agarosa, que va a unir a la etiqueta Stag. Finalmente, analizamos tanto la expresión de las diferentes proteínas de fusión como las proteínas de la IP mediante Western Blot (figura 5).

Se puede observar una buena expresión tanto en TULP3 como en las distintas fusiones con los dominios C-terminales de los GPCRs (figura 5A). Por otro lado, podemos observar una buena inmunoprecipitación de TULP3 en todos los casos. Por último, observamos la proteína TULP3 biotinilada donde se ven grandes diferencias. Por un lado, al comparar el receptor no ciliar B2AR con el receptor ciliar Htr6 vemos diferencias significativas ya que en el receptor Htr6 se produce una biotinilación de TULP3 mientras que el receptor B2AR apenas se genera lo que significa que el receptor Htr6 está interaccionando con TULP3 mediante el extremo C-terminal. En el caso del mutante Htr6 LLL398AAA, se observa un gran aumento de la cantidad de TULP3 biotinilado con respecto al receptor Htr6 wild type lo que indica que esta mutación aumenta la interacción del receptor con TULP3. Por otro lado, el mutante Htr6 ${ }_{\triangle 373-440}$ pierde la interacción con TULP3 ya que apenas hay biotinilación mientras que el mutante $\mathrm{Htr}_{\triangle 408-440}$ biotiniliza tanto TULP3 como el receptor Htr6 wild type. 
A

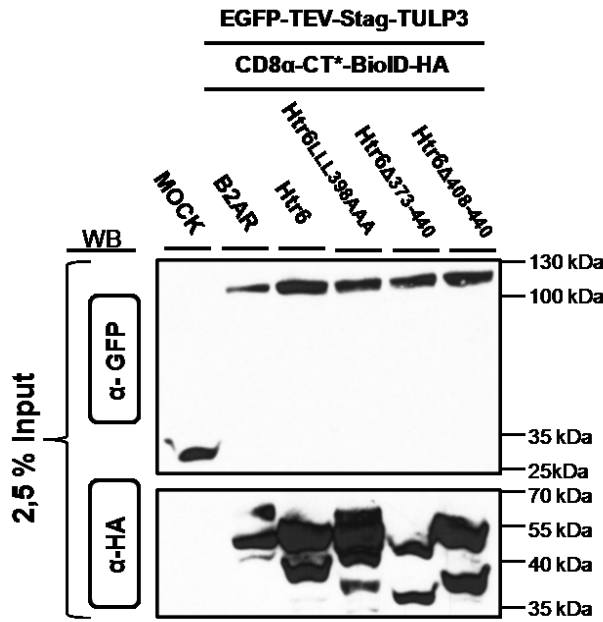

B

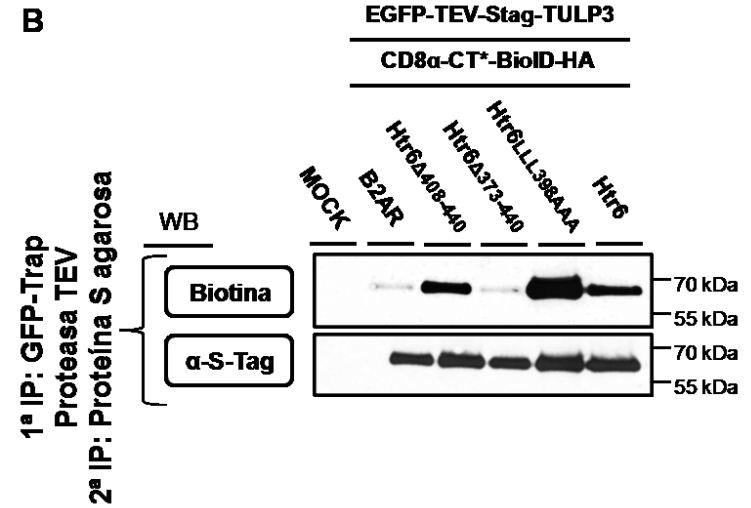

Figura 5.- Hay diferencias en la biotinilación de TULP3 entre el receptor Htr6 wild type, y los mutantes Htr6 Lll398AAA y Htr6 ${ }_{\triangle 373-440 .}$. (A) Western Blot del lisado de proteínas para estudiar la expresión de las diferentes proteínas de fusión. * Banda correspondiente a la proteína EGFP (B) Western Blot de la proteína TULP3 inmunoprecipitada total y de la proteína TULP3 biotinilada. * El orden del WB de la IP es distinto al orden del WB de lisado debido a un fallo al cargar el gel.

\section{El extremo C-terminal de TULP3 interacciona con el extremo C-terminal de Htr6}

A partir de los resultados del experimento anterior, realizamos otro ensayo de proximidad mediante biotinilación para estudiar si el C-terminal de Htr6 interacciona con el dominio N-terminal (del aminoácido 1 al 183)y/o con el dominio C-terminal (del aminoácido 184 al 442)de la proteína TULP3. Para ello, vamos a estudiar la interacción entre el dominio N-terminal (NTD) y el dominio C-terminal de TULP3 con el dominio C-terminal de Htr6 wild type y el dominio C-terminal del mutante Htr6 LLL398AAA, $_{2}$ donde se observa un aumento de la biotinilación de la proteína TULP3.

Observamos una buena expresión de los diferentes dominios C-terminales de los GPCRs y del dominio N-terminal de TULP3. Sin embargo, no se observa expresión del dominio C-terminal de TULP3 (figura 6A). Por otro lado, vemos inmunoprecipitación tanto del dominio N-terminal como del dominio Cterminal de la proteína TULP3, lo que nos indica que ha habido expresión del dominio C-terminal pero menos que en el dominio N-terminal y debido a que solo cargamos un $2.5 \%$ de la cantidad proteica total, no logramos ver la expresión del dominio C-terminal en el Western Blot (figura 2B).

Si nos fijamos en la proteína TULP3 biotinilada vemos grandes diferencias. Por un lado, observamos que el dominio N-terminal de la proteína TULP3 apenas se biotinila por lo que no interacciona con el Cterminal de los GPCRs. Sin embargo, el dominio C-terminal de TULP3 interacciona tanto con el dominio C-terminal del receptor Htr6 wild type como con el dominio C-terminal del mutante Htr6LlL398AAA, ya que se observa una biotinilación similar en relación con la cantidad de TULP3 inmunoprecipitado (figura 6B).

A

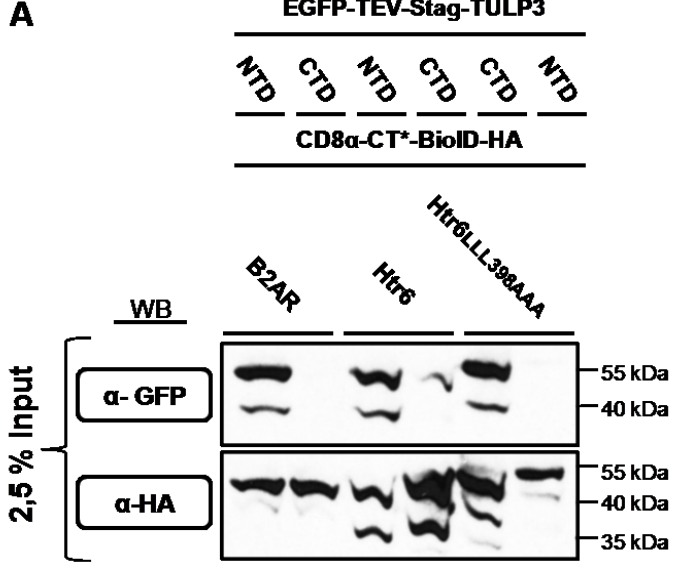

B

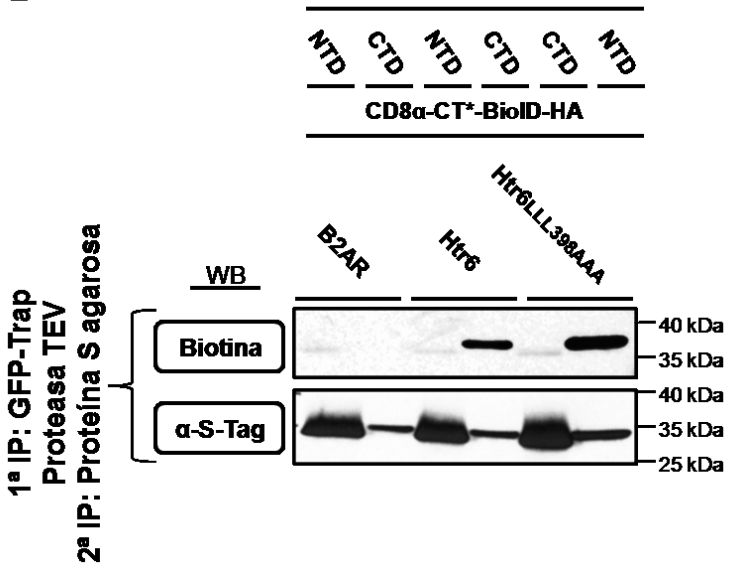

Figura 6.- El extremo C-terminal de TULP3 se biotiniliza a diferencia del extremo N-terminal que no sufre biotinilación. (A) Western Blot del lisado de proteínas para estudiar la expresión de las diferentes proteínas de fusión. * Banda correspondiente a la proteína EGFP (B) Western Blot de la proteína TULP3 inmunoprecipitada total y de la proteína TULP3 biotinilada. * CTD, dominio Cterminal; NTD, dominio N-terminal. 


\section{Discusión}

En este trabajo hemos estudiado, en primer lugar, la interacción entre la proteína Cdk5 y el receptor Htr6 mediante su sobreexpresión en células HEK293T. En el primer ensayo de coinmunoprecipitación no hemos observado interacción entre ambas proteínas. Sin embargo, como esta interacción estaba ya descrita en células NG108-15 [6] decidimos probar otro experimento y para ello, realizamos un tratamiento con serotonina (5HT), ligando del receptor Htr6. De este modo se activó el receptor para comprobar si se producía un cambio conformacional necesario para la interacción del receptor Htr6 con la proteína Cdk5. No obstante, tampoco observamos ninguna interacción.

Los resultados encontrados nos indican que probablemente sea necesario algo más que tener las proteínas sobreexpresadas en células HEK293T para que se dé la interacción que tendrían las células NG108-15, somáticas híbridas generadas a partir de neuroblastoma de ratón y glioma de rata. Se ha visto que Cdk5 se activa por las proteínas p35 y p39, posteriormente se une al receptor Htr6 y por último, fosforila dicho receptor [6]. Por lo tanto, se podría activar a Cdk5 para analizar si de este modo interacciona con el receptor Htr6. Por otro lado, se piensa que la unión de Cdk5 al receptor Htr6 y la posterior fosforilación del receptor es independiente de la activación de Htr6 por ligando [6]. Esto podría explicar por qué no vemos diferencias en la interacción entre Cdk5 y el receptor Htr6 al tratar las células con serotonina.

Tanto en el primer como en el segundo experimento hemos observado una inmunoprecipitación inespecífica de Cdk5 con las beads de Myc, por lo que podríamos utilizar diferentes proteínas de fusión para Htr6 con otra etiqueta, como EGFP, para evitar esta inespecificidad.

El otro ensayo que realizamos es el estudio de proximidad entre proteínas mediante biotinilación. En el primer experimento observamos que TULP3 no interacciona con el dominio C-terminal del receptor no ciliar B2AR; y tampoco con el dominio C-terminal del mutante Htr6 ${ }_{\Delta 373-440 \text {, donde se eliminan los }}$ residuos 373-440. Sin embargo, vemos una interacción similar entre TULP3, y el dominio C-terminal del receptor Htr6 wild type y del mutante Htr6 ${ }_{\triangle 408-440}$ en el cual se han eliminado los residuos 408-440. Esto nos indica por un lado que el extremo C-terminal del receptor Htr6 interacciona con la proteína TULP3 y más específicamente que los residuos de 373 al 407 son importantes para esta interacción. Además, se observa un aumento de la interacción de TULP3 con el dominio C-terminal cuando mutamos las tres leucinas (del residuo 398 al 401) a alaninas.

Anteriormente se había observado que tanto la mutación LLL398AAA como la mutación $\Delta 373-440$ disminuyen la localización ciliar [datos lab. García-Gonzalo, F.], mientras que ahora se ha observado que se producen cambios en la interacción con TULP3 con respecto al receptor Htr6 wild type. Por otro lado, el modelo de transporte de GPCRs al cilio explica que debe producirse una unión a TULP3 y luego una posterior liberación [8]. Por lo tanto, estos resultados se podrían explicar con este modelo ya que en el caso del mutante Htr6 ${ }_{\triangle 373-440}$ no se produciría transporte al interior del cilio, pues no interaccionaría con TULP3; y por otro lado, en el caso del mutante Htr6 LLL398AAA no se produciría la separación del receptor Htr6 y TULP3, por lo que tampoco se transportaría al cilio.

En el último experimento, estudiamos las interacciones de los dominios N-terminal y C-terminal de la proteína TULP3 con los dominios C-terminales de los receptores B2AR, Htr6 wild type y Htr6 LLL398AAA. Observamos que el extremo C-terminal de los receptores Htr6 y Htr6 LlL398AAA interaccionan con el dominio C-terminal de TULP3. Estos resultados eran lo que esperábamos ya que el modelo de transporte de GPCRs al cilio expone que la interacción del GPCR a TULP3 se produce mediante la CLS que interacciona con el dominio C-terminal de TULP3. Por lo tanto, podemos decir que la interacción del receptor Htr6 con TULP3 se produce a través de la CLS del dominio C-terminal del receptor Htr6 y el dominio C-terminal de TULP3.

Este experimento nos esclarece la interacción de la proteína adaptadora TULP3 con el receptor Htr6. Se podrían realizar futuros experimentos en los que mutáramos el dominio tubby de la proteína TULP3 para analizar si el receptor Htr6 interacciona mediante este dominio de interacción con fosfoinosítidos. Además, se podrían hacer más ensayos para localizar la secuencia concreta del receptor Htr6 con la cual interacciona. También se podrían realizar estos experimentos en otras proteínas ciliares de membrana cuyo transporte al cilio se desconoce como es el caso del receptor Sstr3 de la somatostatina, se ha visto que este receptor tiene una CLS en el extremo C-terminal aparte de su CLS ya descrita del tercer lazo intracelular como ocurre en el receptor Htr6 [7] [datos lab. García-Gonzalo, F.].

Todos estos resultados nos muestran por un lado, que debemos cambiar la manera de estudiar las interacciones de las proteínas efectoras con el receptor Htr6. Por otro lado, nos muestran la importancia de la CLS del dominio C-terminal de Htr6 para su transporte al cilio y además, nos acercan más al modelo de transporte ciliar. Podría considerarse un gran avance para continuar estudiando el tráfico ciliar de las proteínas ciliares de membrana y por lo tanto, las vías de señalización ciliar en las que intervienen estas proteínas. 


\section{Bibliografía}

1. Hilgendorf, K. I., Johnson, K. T. and Jackson, P.K. 2016. The primary cilium as a cellular receiver: organizing ciliary GPCR signaling. Current Opinion in Cell Biology. 39:84-92.

2. Waters, A.M. and Beales, P.L. 2011. Ciliopathies: an expanding disease spectrum. Pediatric Nephrology. 26 (7):1039-1056.

3. Hamon, M., Doucet, E., Lefevre, K., et al. 1999. Antibodies and antisense oligonucleotide for probing the distribution and putative functions of central 5-HTR6 receptors. Neuropsychopharmacology. 21:68-76

4. Brailov, I., Bancila, M., Brisorgueil, M. J., et al. 2000. Localization of 5-HT(6) receptors at the plasma membrane of neuronal cilia in the rat brain. Brain Research. 872(1-2):271-275

5. Meffre, J., Chaumon-Dubel, S., Mannoury la Cour, C., et al. 2012. 5-HT6 receptor recruitment of mTOR as a mechanism for perturbed cognition in schizophrenia. EMBO Molecular Medicine. 4:1043-1056.

6. Duhr, F., Déléris, P., Raynaud, F., et al. 2014. Cdk5 induces constitutive activation of 5-HT6 receptors to promote neurite growth. Nature Chemical Biology. 10:590-597.

7. Berbari, N. F., Johnson, A. D., Lewis, J. S.,K.et al. 2008. Identification of Ciliary Localization Sequences within the Third Intracellular Loop of G Protein-coupled Receptors. Molecular Biology of the Cell. 19:1540-1547.

8. Badgandi, H. B., Hwang, S., Shimada, I. S., et al. 2017. Tubby family proteins are adapters for ciliary trafficking of integral membrane proteins. The Journal of Cell Biology. 216(3):743-760.

9. Kim, D. I., Jensen, S. C., Noble, K. A., et al. 2016. An improved smaller biotin ligase for BioID proximity labeling. Molecular Biology of the Cell. 27(8):1188-1196. 